\title{
Caso Martínez Coronado vs. Guatemala
}

Sentencia de 10 de mayo de 2019

El 10 de mayo de 2019 la Corte Interamericana de Derechos Humanos (en adelante "la Corte" o "este Tribunal") dictó Sentencia mediante la cual declaró al Estado responsable por: i) la violación del principio de legalidad consagrado en el artículo 9 de la Convención Americana sobre Derechos Humanos, en relación con la obligación de garantizar los derechos establecida en el artículo 1.1 y 2 de la Convención, y en violación de los artículos 4.1 y 4.2 de la Convención Americana sobre Derechos Humanos, en relación con la obligación de garantizar los derechos establecida en el artículo 1.1, y ii) la violación del derecho a las garantías judiciales, consagrado en los artículos 8.2.c) y 8.2.e) de la Convención Americana sobre Derechos Humanos, en relación con la obligación de garantizar los derechos establecida en el artículo 1.1 de la Convención, todas en perjuicio del señor Manuel Martínez Coronado (en adelante "señor Martínez Coronado").

\section{Consideraciones previas}

La Corte concluyó que el señor Manuel Martínez Coronado es la única víctima en el presente caso y no corresponde admitir a los familiares del señor Martínez Coronado como presuntas víctimas, puesto que no fueron incluidos en el Informe de Fondo de la Comisión, y no se presenta alguna de las excepciones previstas en el artículo 35.2 del Reglamento de la Corte. 


\section{Hechos}

Contexto sobre la normativa en Guatemala: El artículo 18 de la Constitución de Guatemala al momento de los hechos reconoce la posibilidad de que se aplicara la pena de muerte. Además, el artículo 132 del Código Penal vigente en 1995 tipificaba el asesinato considerando "la pena de muerte en lugar del máximo de prisión, si por las circunstancias del hecho y de la ocasión, la manera de realizarlo y los móviles determinantes, se revelare una mayor y particular peligrosidad del agente".

Por otro lado, el artículo 95 del Código Procesal Penal, vigente al momento de los hechos, indica que, "la defensa de varios imputados en un mismo procedimiento por un defensor común es, en principio, inadmisible. El tribunal competente, según el periodo del procedimiento, o el Ministerio Público podrá permitir la defensa común cuando, manifiestamente, no exista incompatibilidad. Cuando se advierta la incompatibilidad, podrá ser corregida de oficio, proveyendo a los reemplazos necesarios, según está previsto para el nombramiento de defensor".

Además, el 11 de febrero de 2016 la Corte de Constitucionalidad de Guatemala declaró inconstitucional el segundo párrafo del artículo 132 del Código Penal, relativo a la peligrosidad del agente como criterio para aplicar la pena de muerte, así como también indicó que esta declaratoria tiene efectos "generales".

Hechos relacionados con las circunstancias personales de la presunta víctima, así como sobre el proceso penal y la ejecución del señor Manuel Martínez Coronado: El señor Manuel Martínez Coronado, junto con un co-imputado fueron acusados por el delito de asesinato de siete personas, por hechos ocurridos el 16 de mayo de 1995 en la aldea El Palmar. En el proceso penal el señor Martínez Coronado y su co-imputado fueron representados por un defensor común nombrado de oficio.

El 26 de octubre de 1995 el Tribunal de Sentencia Penal, Narcoactividad y Delitos contra el Ambiente del Departamento de Chiquimula declaró a ambos imputados como responsables de siete delitos de asesinato, condenando al señor 
Martínez a pena de muerte por medio de inyección letal, pena fundamentada en la peligrosidad del agente, y luego de negar todo valor probatorio a su declaración debido a que presentaba notorias contradicciones con la declaración rendida por el otro co-imputado.

Luego de la sentencia de 26 de octubre de 1995 el señor Martínez Coronado, representado por su abogado defensor, interpuso distintos recursos, presentó acciones de amparo contra la sentencia condenatoria, y un recurso de gracia, los cuales resultaron infructuosos y el 10 de febrero de 1998 el señor Manuel Martínez Coronado fue ejecutado, por medio de inyección letal.

\section{Fondo}

La responsabilidad del Estado fue analizada en el siguiente orden: 1) Derecho a la vida y principio de legalidad y retroactividad, y 2) Derecho a las garantías judiciales.

1) DERECHO A LA VIDA Y PRINCIPIO DE LEGALIDAD Y DE RETROACTIVIDAD (Artículos 4 y 9 de la Convención Americana sobre Derechos Humanos, en relación con los artículos 1.1 y 2 del mismo instrumento)

La Corte previamente resaltó la importancia de proteger el derecho a la vida y señaló que el artículo 4 de la Convención establece un régimen claramente restrictivo de la pena de muerte, como se infiere de la lectura de sus numerales 2 , $3,4,5$ y 6 . De forma tal que esta disposición revela una inequívoca tendencia limitativa y excepcional en el ámbito de imposición y de aplicación de dicha pena. La finalidad que se persigue es avanzar hacia una prohibición definitiva a esta modalidad de sanción penal, a través de un proceso progresivo e irreversible destinado a cumplirse en los Estados que han suscrito la Convención Americana. De tal manera que la decisión de un Estado Parte en la Convención Americana, cualquiera sea el tiempo en que la haya adoptado, en el sentido de abolir la pena de muerte se convierte, ipso jure, en una resolución definitiva e irrevocable. En 
esta materia la Convención apunta hacia una progresiva eliminación, al adoptar las salvaguardias necesarias para restringir definitivamente su aplicación y su ámbito, de modo que éste se vaya reduciendo hasta su supresión total. Recordó lo señalado por este Tribunal en su Opinión Consultiva OC-3/83 sobre la pena de muerte. Además, destacó que la tendencia abolicionista se encuentra recogida en los considerandos y artículos 1 y 2 del Protocolo a la Convención Americana sobre Derechos Humanos relativo a la Abolición de la Pena de Muerte, y exhorta a los Estados que aún no han suscrito el Protocolo, a suscribirlo y a proscribir esta modalidad de sanción penal. Todo ello en armonía con la también tendencia abolicionista imperante en el sistema universal de protección de los derechos humanos.

Seguidamente, la Corte estableció que en el presente caso para determinar la condena del señor Martínez Coronado se aplicó el artículo 132 del Código Penal guatemalteco vigente para dicha fecha, en el que se regulaba el tipo penal de asesinato. En el caso en concreto, se condenó a pena de muerte al señor Martínez Coronado en aplicación del segundo párrafo de dicha norma, que preveía la aplicación de dicha pena "si por las circunstancias del hecho y de la ocasión, la manera de realizarlo y los móviles determinantes, se revelare una mayor y particular peligrosidad del agente".

La Corte señaló que ya ha tenido la oportunidad de pronunciarse específicamente sobre la aplicación del referido artículo 132 del Código Penal y el concepto de "peligrosidad futura" en el caso Fermín Ramírez vs. Guatemala, y siguiendo esta lógica, en la Sentencia el Tribunal determinó que, el empleo del criterio de peligrosidad del agente, tanto en la tipificación de los hechos del ilícito penal cometido por el señor Martínez Coronado, como en la determinación de la sanción correspondiente, resulta incompatible con el principio de legalidad previsto en la Convención Americana. El examen de la peligrosidad del agente implica la valoración por parte del juzgador de hechos que no han ocurrido y, por lo tanto, supone una sanción basada en un juicio sobre la personalidad del infractor y no en los hechos delictivos imputados conforme la tipificación penal aplicable. La Corte destacó que la vulneración del principio de legalidad en el presente caso se encuentra configurada por dos elementos: a) la indeterminación del concepto de "peligrosidad futura" contenido en el artículo

\section{8}


132 del Código Penal, y b) la aplicación al señor Martínez Coronado de la sanción prevista (la pena de muerte) en dicha disposición. En consecuencia, este Tribunal estima que el Estado fue responsable por la violación al artículo 9 de la Convención Americana, en relación con los artículos 1.1 y 2 de la Convención, en perjuicio del señor Martínez Coronado.

En el presente caso, el 10 de febrero de 1998 el señor Martínez Coronado fue ejecutado, mediante inyección letal. Dada la aplicación de la pena de muerte impuesta con base en una norma contraria a la Convención Americana, este Tribunal declaró que el Estado es responsable de la violación de los artículos 4.1 y 4.2 de la Convención Americana, en relación con el artículo 1.1 del mismo instrumento, en perjuicio del señor Martínez Coronado.

2) DERECHO A LAS GARANTÍAS JUDICIALES (Artículo 8 de la Convención Americana sobre Derechos Humanos, en relación con el artículo 1.1 del mismo instrumento)

El caso se relaciona con la aducida falta de las garantías mínimas para una adecuada defensa en el presente caso, y por lo tanto deben ser analizados bajo los presupuestos del artículo 8.2 de la Convención Americana.

Este Tribunal notó que en el presente caso, es un hecho no controvertido que el 18 de mayo de 1995 en su indagatoria, el señor Martínez Coronado solicitó que, en razón de su situación económica le fuera nombrado un defensor de oficio, por ende, el 19 de mayo de 1995 se le designa un abogado como su defensor. Es un hecho no controvertido que también figuró como defensor de DA, co-imputado del señor Martínez Coronado. Consta además que el defensor nombrado originalmente fue sustituido posteriormente, y en su lugar, se nombró a RARM como defensor común de ambos imputados.

En el presente caso, la Corte consideró que la discusión jurídica que corresponde analizar se refiere a la compatibilidad con la Convención, y particularmente, con el derecho a la defensa del señor Martínez Coronado, de que el Estado le haya 
proporcionado una defensa común de oficio a la presunta víctima y a otro coimputado.

Como punto de partida la Corte constató que el artículo 95 del Código Procesal Penal indica que "[1]a defensa de varios imputados en un mismo procedimiento por un defensor común es, en principio, inadmisible. El tribunal competente, según el período del procedimiento, o el Ministerio Público podrá permitir la defensa común cuando, manifiestamente, no exista incompatibilidad. Cuando se advierta la incompatibilidad, podrá ser corregida de oficio, proveyendo a los reemplazos necesarios, según está previsto para el nombramiento de defensor". Por lo tanto de conformidad con dicho texto, en principio la defensa común de los imputados tanto si es provista por sus abogados de confianza o por aquellos designados por el Estado a través de la defensa pública está prohibida $\mathrm{y}$, solo se permite excepcionalmente en caso de que no exista manifiesta incompatibilidad.

Este Tribunal consideró que correspondería al Estado, mediante las autoridades competentes, identificar si existen dichas incompatibilidades y adoptar las medidas conducentes para que se garantice el derecho a la defensa de los co-imputados involucrados. Este principio es especialmente relevante en casos donde los imputados puedan enfrentar una condena severa, como es la pena de muerte. Por otra parte, la existencia de inconsistencias en las declaraciones realizadas por los co-imputados en el marco de un proceso penal no demuestra necesariamente una incompatibilidad en sus defensas e intereses que impida una defensa común.

No obstante, en el caso concreto la contradicción existente en las declaraciones de los co-imputados recae sobre elementos sustanciales de la versión de los hechos propuesta por el señor Martínez Coronado, de forma tal que la contradicción le privó de un elemento sustancial de su defensa. En esa medida, en este caso las inconsistencias en las declaraciones por parte de los coimputados debieron ser advertidas por la defensa común, quien debió ponerlas en conocimiento del tribunal para efectos de que se nombrara otro defensor, o incluso las autoridades judiciales encargadas de dirigir el proceso debieron adoptar de oficiolas medidas pertinentes para garantizar el derecho a la defensa por tratarse de una defensa pública proporcionada por el Estado. 
En consecuencia, la Corte concluyó que el Estado incumplió con su deber de asegurar el derecho irrenunciable de ser asistido por un defensor proporcionado por el Estado que le garantizara al inculpado los medios adecuados para su defensa, en violación de los artículos 8.2.c) y 8.2.e) de la Convención Americana, en la medida que la defensa común, vulneró los derechos del señor Manuel Martínez Coronado. Es decir, el Estado incumplió con su deber de brindarle las garantías mínimas necesarias para una adecuada defensa. 